\title{
Introducing the Iron Potential Zones Using Remote Sensing Studies in South of Qom Province, Iran
}

\author{
Faranak Feizi*, Edris Mansouri \\ Department of Mining Engineering, Faculty of Engineering, South Tehran Branch, Islamic Azad University, Tehran, Iran \\ Email: *F_Feizi@azad.ac.ir
}

Received March 18, 2013; revised April 18, 2013; accepted May 10, 2013

Copyright (C) 2013 Faranak Feizi, Edris Mansouri. This is an open access article distributed under the Creative Commons Attribution License, which permits unrestricted use, distribution, and reproduction in any medium, provided the original work is properly cited.

\begin{abstract}
The studied area-Kermejegan — is located in the south of Qom Province, Iran. In this paper, geology map, ASTER and ETM7+ satellite images were used and after processing these images with Geomatica and ENVI softwares, iron potential zones were compared with the iron mine position in the south of the area and 2 dominate indexs around. Finally remote sensing, faults and geological data layers were integrated in GIS and hopeful zones were introduced for continuing the exploration processes.
\end{abstract}

Keywords: Remote Sensing; Geology; Lithology; Alteration; Integrate; Kermejegan

\section{Introduction}

The use of satellite images for mineral exploration has been very successful in pointing out the presence of minerals such as alunite, pyrophyllite, kaolinite, sericite, illite, muscovite, smectite, and carbonate which are important in the identification of hydrothermal alterations [1]. In addition, satellite remote sensing provides synoptic view, which is helpful in identification and delineation of various land forms, linear features and structural elements $[2,3]$. Hence, in primary stages, mapping geologic lineaments are important as long-range management for mineral exploration, because of their potentials for harboring ore bodies that are carried and deposited by ascending hydrothermal fluids [4]. Iran is located in the Alpine-Himalian orogenic and metalogenic belt and has high potentials for gold and copper and other base metal deposits. Satellite images have been used by many Iranian geologist researchers as the cheapest method for interpretation of the structural features and exploration purposes $[5,6]$. For instance, distinguished phyllic, propylitic and argillic alteration zones in the Urumieh-Dokhtar Volcanic Belt of Iran [7], separated a few hydrothermal alterations in the Valayesh in the northwestern Iran [6], distinguished phyllic and argillic alteration zones in the magmatic arc in southeast of Iran [8], separated hydroxyl and iron oxide minerals in the Yazd, central Iran [9], show that satellite images are useful for locating and in-

*Corresponding author. terpretation of the structural features in the Zagros Structural Belt, in southwest of Iran [10]. The aims of the present study are to perform principal component analysis (PCA), apply spectral angle mapper (SAM), Least Square Fit (LS-Fit), Minimum Noise Fraction (MNF) and band ratio to map the iron zones on the ASTER (Advanced Spaceborne Thermal Emission and Reflection Radiometer) and ETM7+ satellite imagery data.

\section{Geology Setting}

Kermejegan area is located between longitudes 481493 487103 and latitudes $3787390-3792893$ in the south of Qom Province, Central Iran (Figure 1). The studied area is a small central part of 1:100000 Kahak geological map. The litho logy of this part includes volcanics such as Andesite, Andesite Basalt to mega porphyry Andesite. Different types of Sandi tuff and Limestone in south and southeast parts and quaternary units are seen in East parts of the area. Hematitization and limonitization are seen in north and southeast part [11]. There is an iron potential zone in southeast of the area with Magnetite and Hematite mineralization in vein and vein lets type which is in detail exploration phase now, showing in the map with green point. Also there are 2 iron mine in southwest of the area which are shown with red points in the map. As the map showing, the main fault-Bidhend-is going throw the south iron potential and central part of the area (Figure 2). 


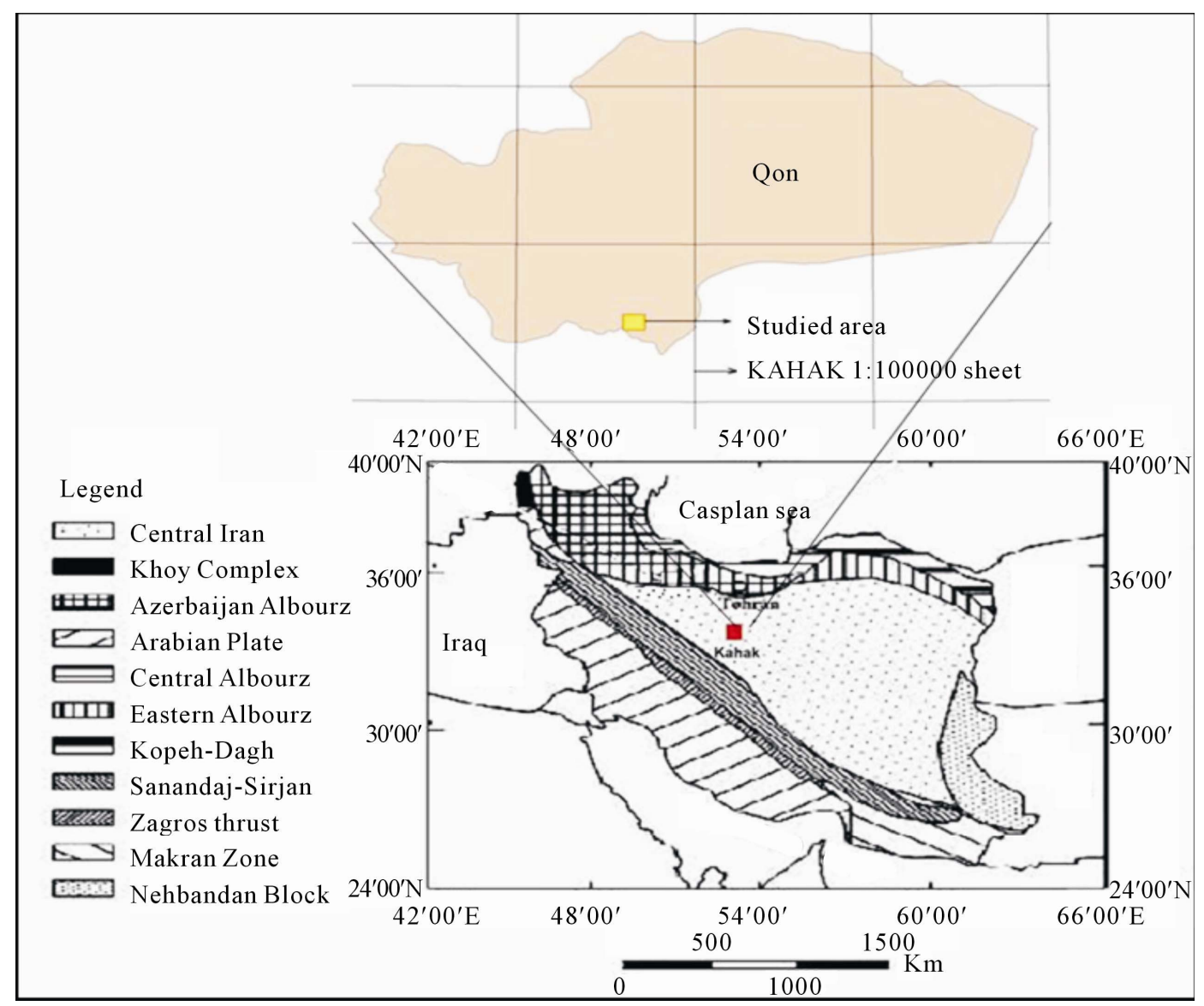

Figure 1. The studied area in the map of Iran.

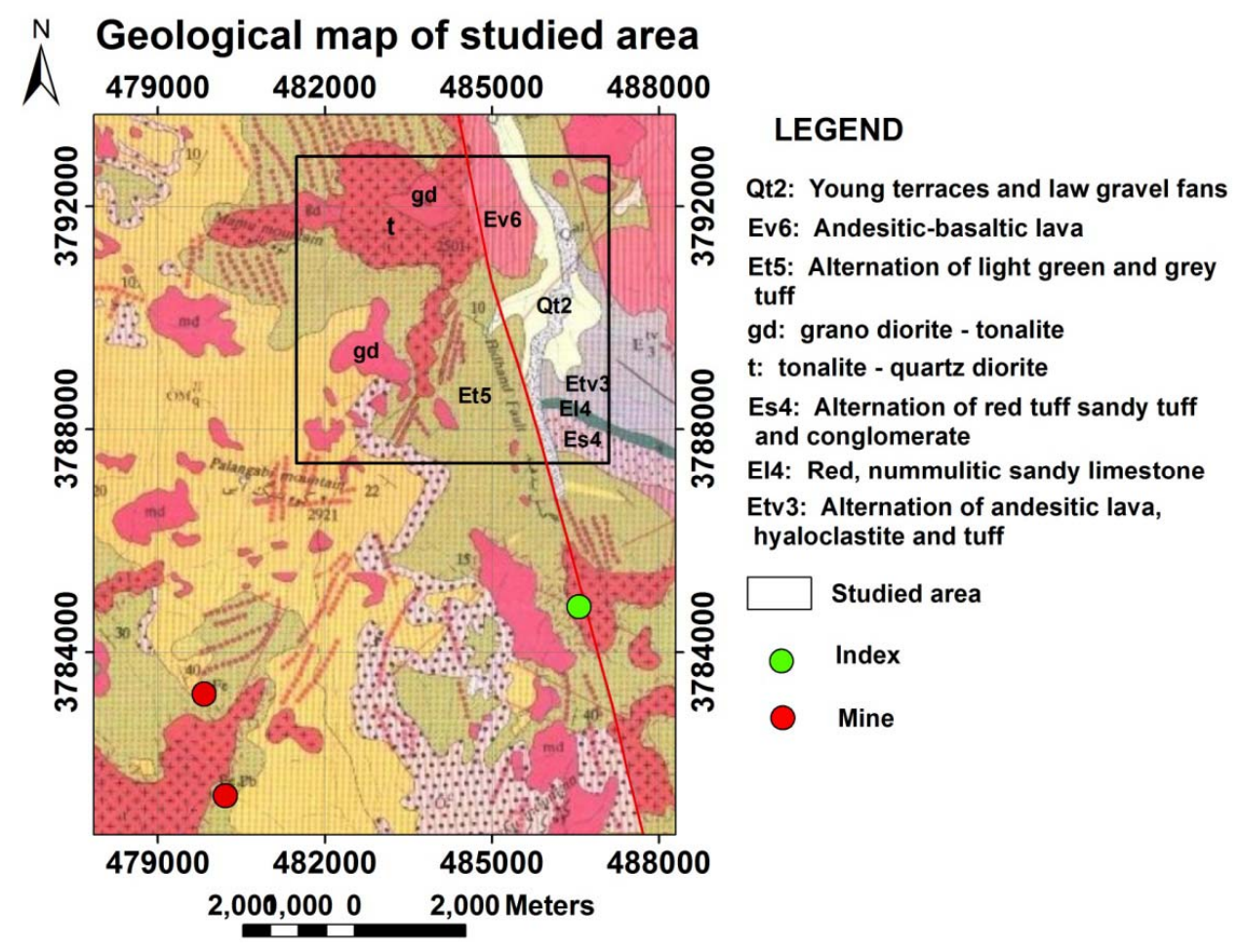

Figure 2. The geological map of studied area (1:100000 Kahak geology map). 


\section{Materials and Methods}

\subsection{ETM7+ Data}

Principal Components Analisys (PCA) method was used for doing this phase.After processing with Geomathica software, RGB: (5 - 7) \& PC2(5 - 7) \& PC4(1,4,5,7) were used. The iron potential zones were shown in goldish yellow by this method (Figure 3).

\subsection{ASTER Data}

The ASTER is an advanced optical sensor comprised of 14 spectral channels ranging from the visible to thermal infrared region. It will provide scientific and also practical data regarding various field related to the study of the earth [12]. Various factors affect the signal measured at the sensor, such as drift of the sensor radiometric calibration, atmospheric and topographical effects. For accurate analysis, all of these corrections are necessary for remote sensing imagery. To this end, at the beginning of the path, data set in hierarchical data format (HDF) was used for this research and radiance correlation such as wavelength, dark subtract and log residual by ENVI4.4 software which is essential for multispectral images, were implemented. For ASTER image processing, MNF LS-Fit PCA SAM methods were used.

\subsection{Integration of Data Layers in GIS}

Data layers have to integrate in GIS for getting any re-
sults.For this reason the geological layer with the location of fault on that should be the main layer and then the iron oxide potential zones which recognized by remote sensing integrated with that. In next step iron mines and indexes integreted with them and at last the final map prepared.

\section{Result and Discussion}

\subsection{Aster and ETM7+ Images Processing}

\subsubsection{Least Squares Fitting}

Least Squares Fitting (LS-Fit) is the technique assumes that the bands used as input values are behaving as the variables of a linear expression and the " $y$ " value of the equation, namely the predicted band information, gives us a calculated output value. This predicted band is what that band should be according to the linear equation. The minerals which are sensitive to a specific band are then differentiated from the features which are reflective to the other bands as well; just by taking the difference between the predicted values and the original values [13].

Distribution of iron oxide was created by using all the 3 visible and near-infrared (VNIR) bands as the input bands and VNIR-b1 as the modeled band (Figure 4).

\subsubsection{Minimum Noise Fraction}

The Minimum Noise Fraction (MNF) transformation is used to determine the inherent dimensionality of image data, segregate noise in the data, and reduce the compu-

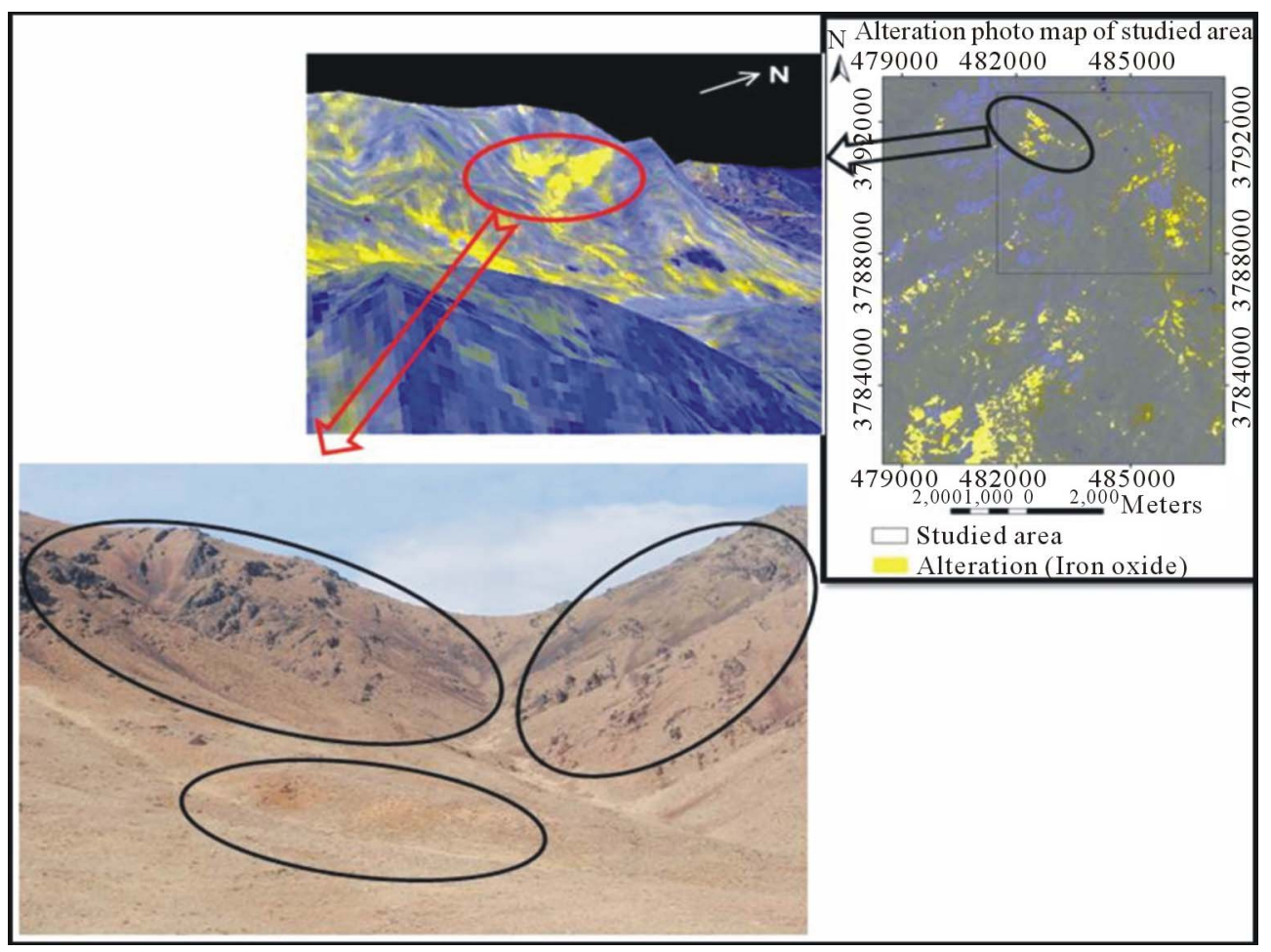

Figure 3. 2 and 3 dimension processing image with check field of iron oxide zones. 


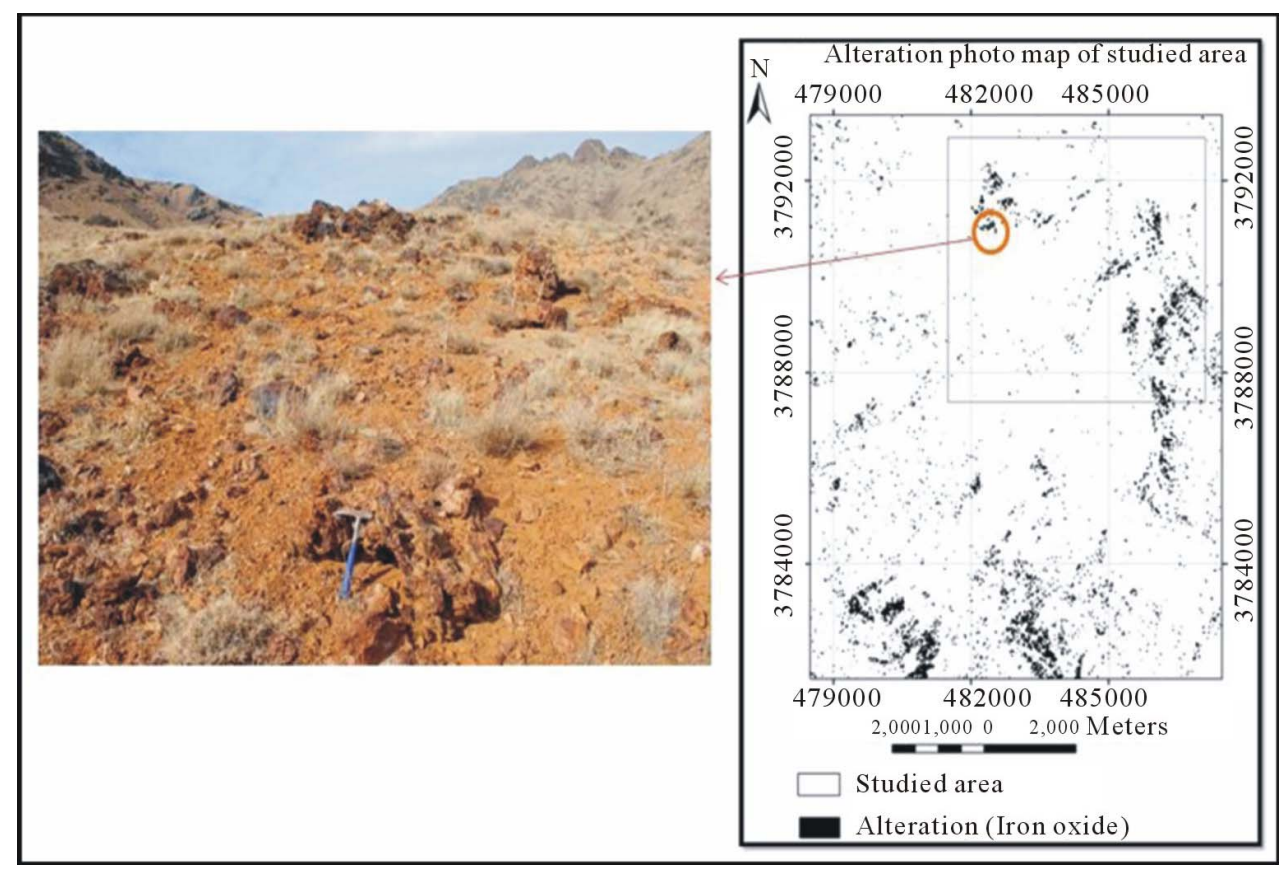

Figure 4. ASTER image processing with LS-Fit method and check field.

tational requirements for subsequent processing [14-16]. MNF involves two steps: in first step which is also called noise whitening, principal components for noise covariance matrix are calculated. This step decorrelates and rescales the noise in the data. In second step principal components are derived from the noise whitened data. The data can then be divided into two parts. One part associated with large Eigen values and the other part with near unity Eigen values and noise dominated images. Using data with large Eigen values separates the noise from the data, and improves spectral results $[15,16]$. MNF analysis can identify the locations of spectral signature anomalies. This process is of interest to exploration geologist because spectral anomalies are often indicative of alterations due to hydrothermal mineralization [16]. MNF band 2, was used for iron oxide alterations (Figure 5).

\subsubsection{Principal Component Analysis}

The Principal Component Analysis (PCA) is a multivariate statistical technique that selects uncorrelated linear combinations (eigenvector loadings) of variables. Each successively extracted linear combination, or principal component (PC), has a smaller variance. PCA is widely used for alteration mapping in metallogenic provinces [17]. PCA technique has been applied in this study. An approach based on the examination of eigenvector loadings in each PC image is used for determining which image contains information related to the spectral signatures of specific target minerals. It is expected that the PC image that collects moderate to high eigenvector loadings for the diagnostic absorptive and reflective bands of the index mineral could be considered as the specific image for that mineral. If the loading of absorptive band is negative in sign, the target area will be enhanced in bright pixels, and if the loading of reflective band is negative, the area will be enhanced in dark pixels $[18,19]$ (Figure 6).

Table 1 shows the eigenvector loadings for bands 1, 2, 3 and 4 . Inverse of PC4 can show the areas with iron oxide.

\subsubsection{Spectral Angle Mapper}

The spectral angle mapper (SAM) is a classification technique that permits rapid mapping by calculating the spectral similarity between the image spectrums to refrence reflectance spectra. The image spectra were compared with USGS Digital Spectral Library (Minerals) [20]. Figure 7 showed selected minerals spectral library plots that related to iron oxide. 4 mineral spectral representative of iron oxide include jarosite, hematite, goethite, limonite was selected (Figure 7). SAM measures the spectral similarity by calculating the angle between the two spectra, treating them as vectors in n-dimensional space [16,21] (Figure 8).

\subsection{GIS Processing}

In this part for integration the data layers in GIS area, first of all, the shape files of all alteration zones which were carried out with different methods were drown. Then the layers were overlapped on each other. Afterwards the most overlapped zones were chosen and were 

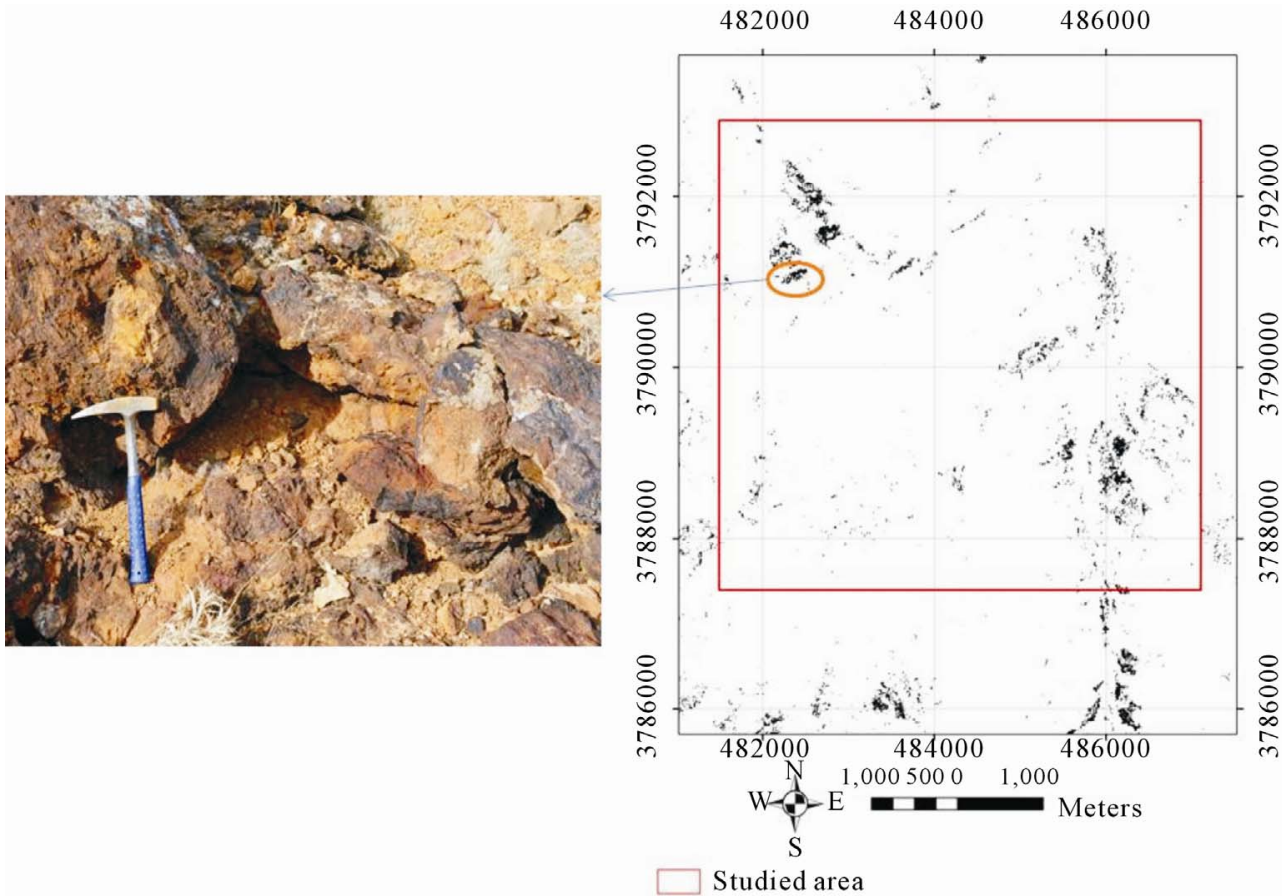

Figure 5. ASTER image processing with MNF method and check field.

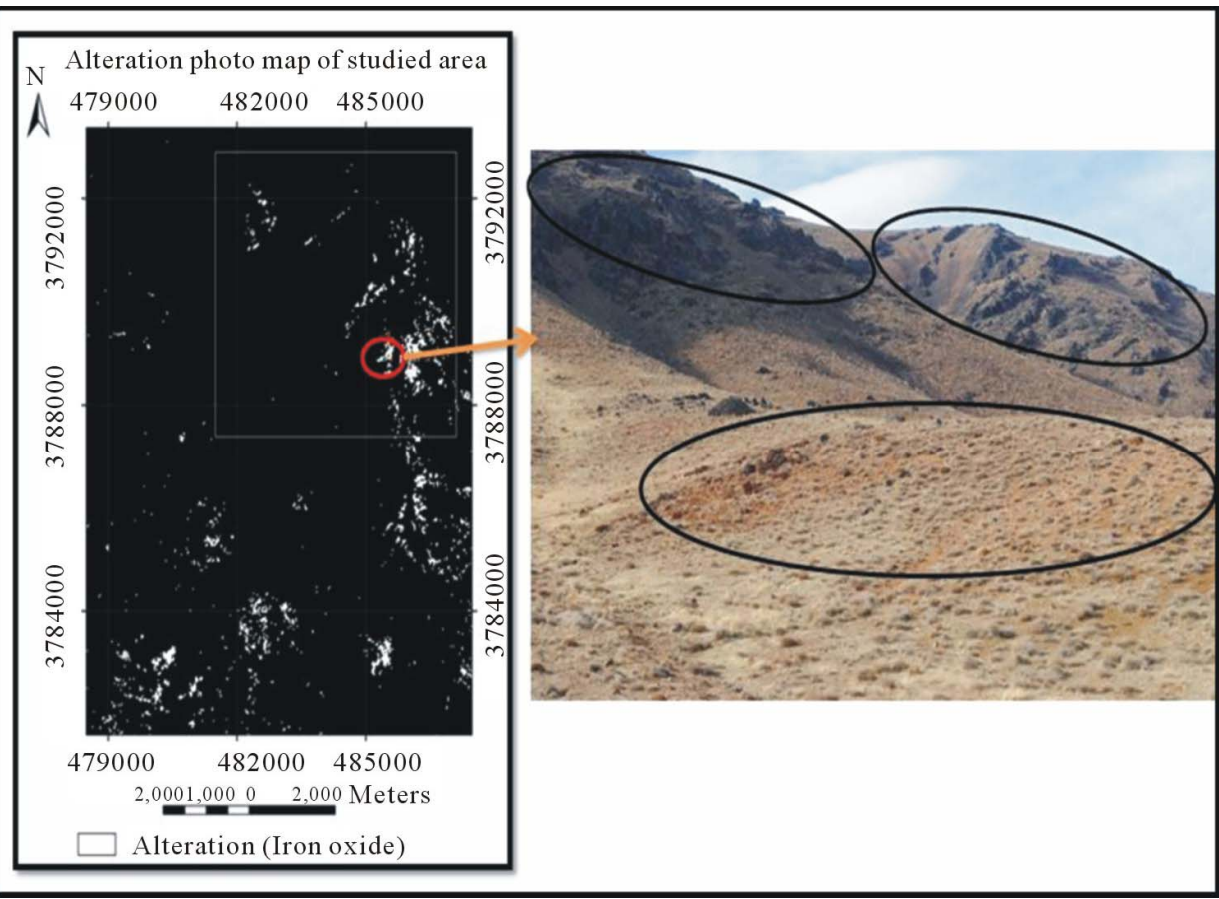

Figure 6. ETM7+ image processing with PCA method and check field.

Table 1. The result of PCA for enhancing iron oxide zone.

\begin{tabular}{ccccc}
\hline Eigenvector & Band 1 & Band 2 & Band 3 & Band 4 \\
\hline Band 1 & 0.392563 & 0.578218 & 0.553369 & 0.453146 \\
Band 2 & 0.710413 & 0.296063 & -0.418364 & -0.482319 \\
Band 3 & 0.005043 & 0.125901 & -0.705904 & 0.697011 \\
Band 4 & 0.584109 & -0.749773 & 0.143019 & 0.276049 \\
\hline
\end{tabular}




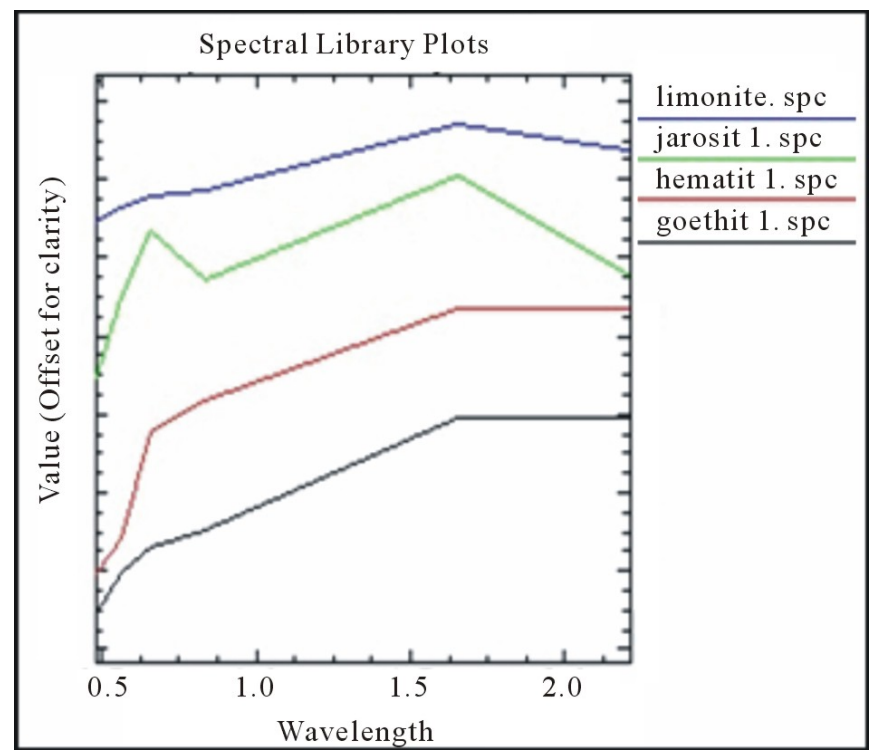

Figure 7. Spectral library plots from USGS library for iron oxide minerals.

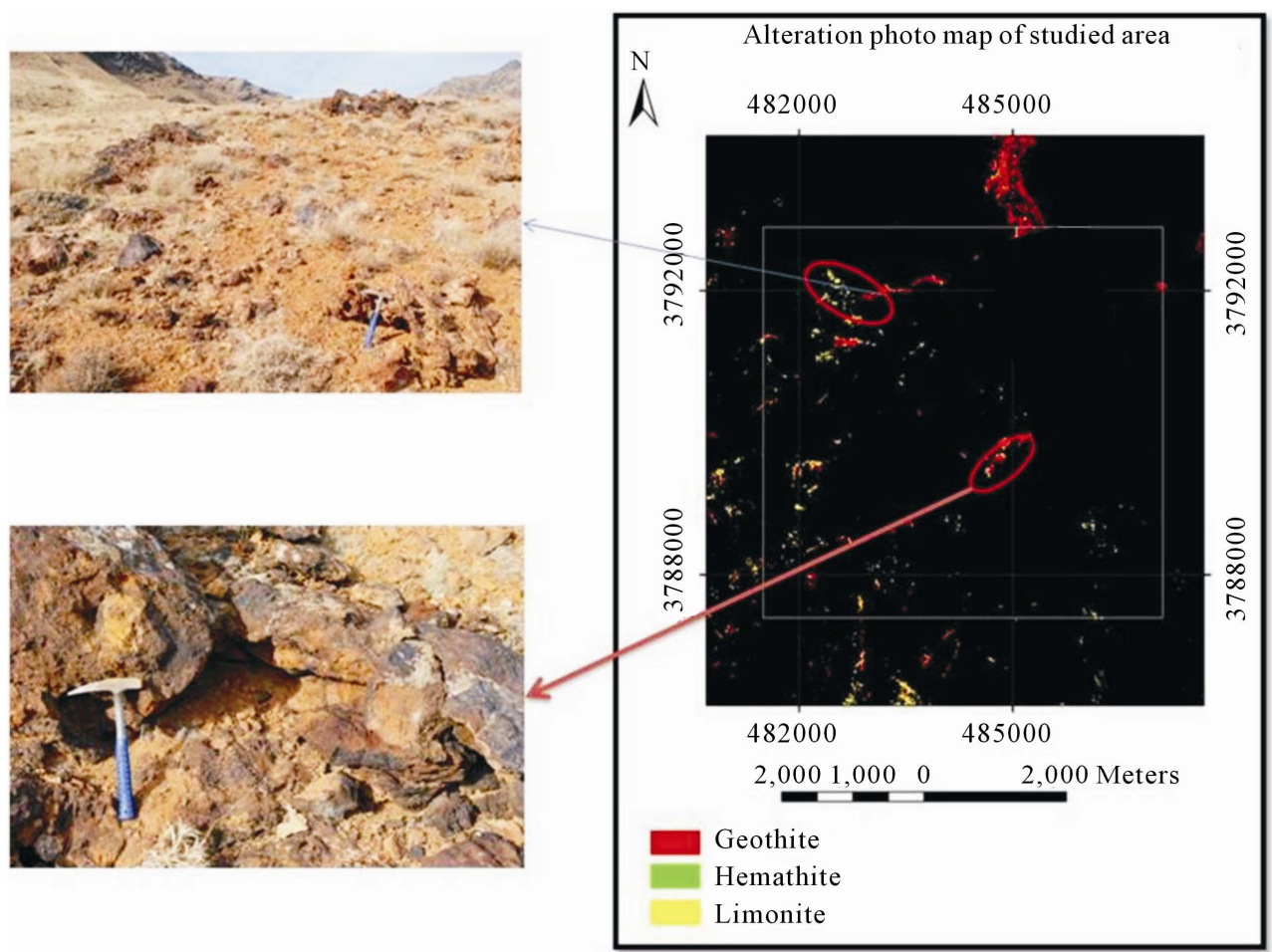

Figure 8. ASTER image processing with SAM method and check field.

controlled with field investigations. As the last step, the geology map of studied area which was shown the iron potentials, was integrated with the final alteration map in GIS area. As it was shown in Figure 9, the iron potential zones (green squares) are similar to south and southeast mines and indexes in litho logy (Tuffs) and intrusive bodies. Also the processed spectrum gradation in those potential zones have good situations. So these two squares have been suggested for more exploration.

\subsection{Comparison between Iron Potential Zones}

After all these software analyses, check field processes were necessary (Figures 3-6 and 8). The control points were detected, and after the check fields, the correction of alteration zones were confirmed. These figures show some check points for iron oxide which were recognized with remote sensing processes. These checks confirmed the results of the RS methods. As the last step the com- 


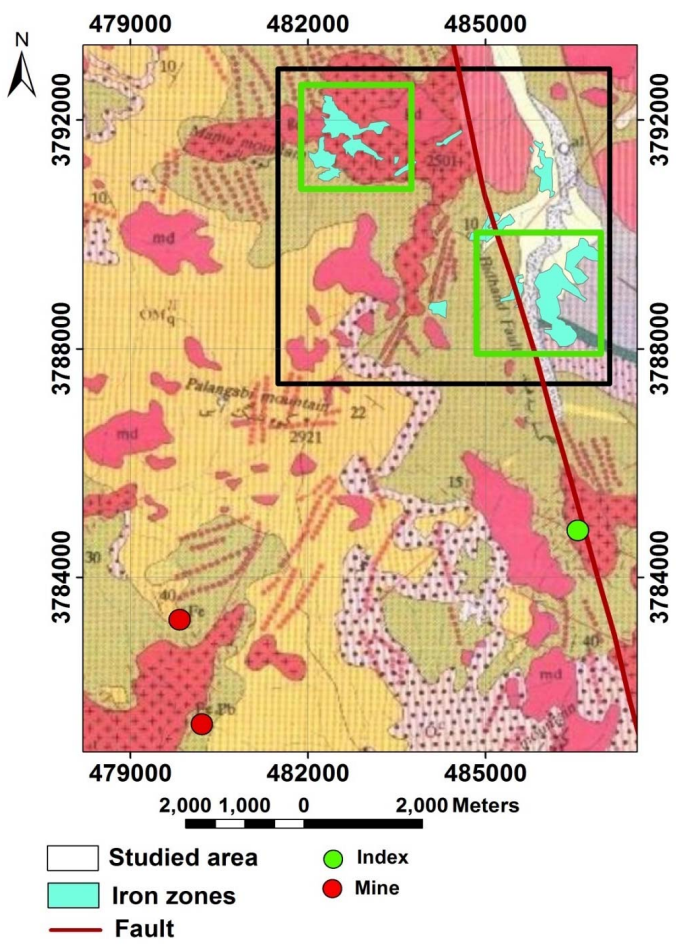

Figure 9. Final map, prepared by GIS.

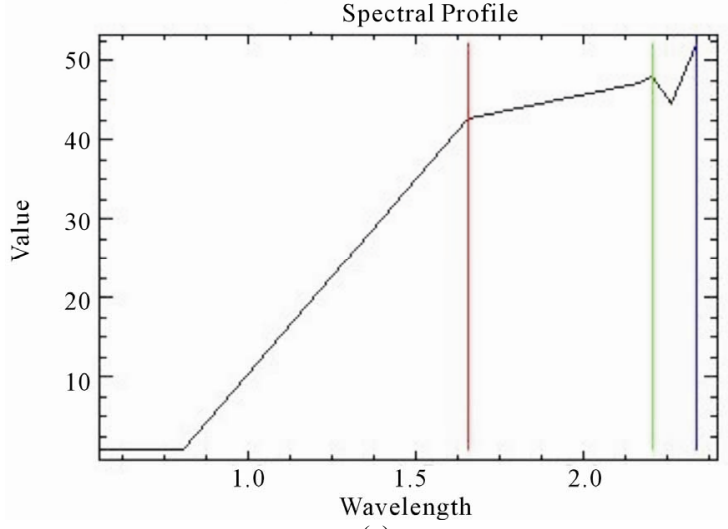

(a)

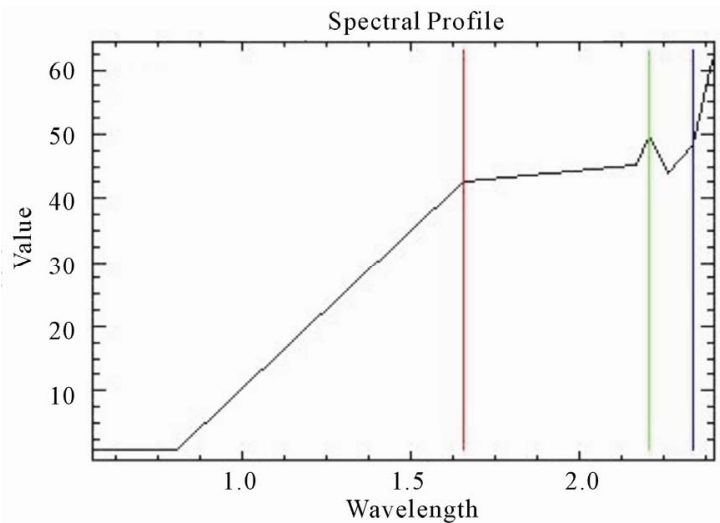

(c)

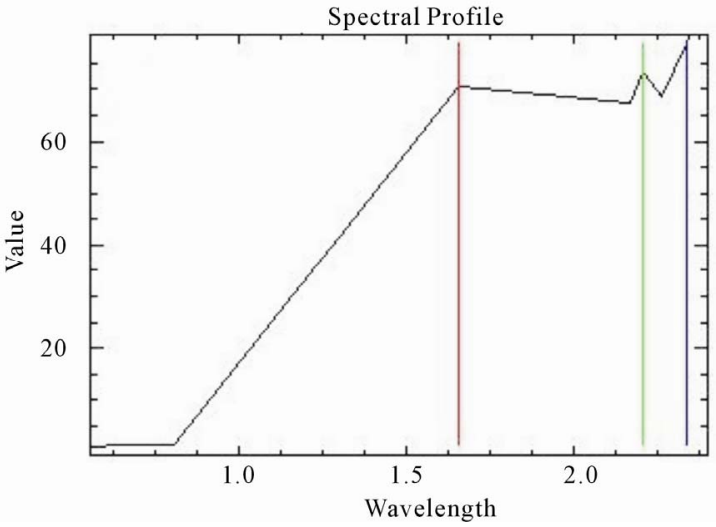

(b)

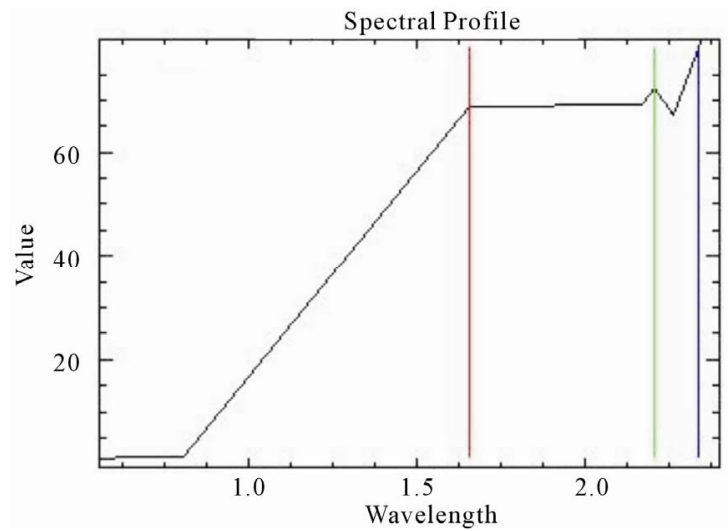

(d)

Figure 10. Z. profile of Fe Index (a), Z. profile of high potential zone in south east of studied area (b), Z. profile of Fe mine (c), Z. profile of high potential zone in north west of studied area (d). 
Table 2. Results of Sarvian Fe mine analyses.

\begin{tabular}{cccc}
\hline \multirow{2}{*}{ Sample No. } & \multicolumn{2}{c}{ Location } & \multirow{2}{*}{ Fe\% Total } \\
\cline { 2 - 3 } & $\mathrm{X}$ & $\mathrm{Y}$ & \\
\hline 1 & 480352 & 3781509 & 38 \\
2 & 480348 & 3781474 & 59 \\
3 & 480356 & 3781422 & 46 \\
\hline
\end{tabular}

parison between two suggested squares zones were necessary. So the $Z$. profiles of these two zones were prepared and compared with the $Z$. profiles of mine and indexes in south of the studied area. As it was shown in Figure 10, these profiles are so similar to each other. So the correction of these two suggested zones was confirmed again. Table 2 shows the results of Fe analyses on Sarvian mine in south of the studied area.

\section{Conclusion}

There are two hopeful areas which suggested for more exploration. Because of the main fault of the studied area going to throw the iron mineralization zones, determination of lineaments in order to connection between structural elements and mineralization has suggested.

\section{REFERENCES}

[1] S. M. Salem, S. A. Arafa, T. M. Ramadan and E. S. A. El Gammal, "Exploration of Copper Deposits in Wadi El Regeita Area, Southern Sinai, Egypt, with Contribution of Remote Sensing and Geophysical Data," Arabian Journal Geoscience, Vol. 6, No. 2, 2011, pp. 321-335. doi:10.1007/s12517-011-0346-Z

[2] A. Javed and M. H. Wani, "Delineation of Groundwater Potential Zones in Kahund Watershed, Eastern Rajasthan, Using Remote Sensing and GIS Techniques," Journal Geological Society of India, Vol. 73, No. 2, 2009, pp. 229236. doi:10.1007/s12594-009-0079-8

[3] M. I. Adham, C. S. Jahan, Q. H. Mazumder, M. M. A. Hossain and A. L. Haque, "Study on Groundwater Recharge Potentiality of Barind Tract, Rajshahi District, Bangladesh Using GIS and Remote Sensing Technique". Journal Geological Society of India, Vol. 75, No. 2, 2010, pp. 432-438. doi:10.1007/s12594-010-0039-3

[4] C. P. Kujjo, "Application of Remote Sensing for Gold Exploration in the Nuba Montains, Sudan," Master of Science Thesis, Bowling Green State University, Wooster, 2010.

[5] H. Asadi Haroni and A. Lavafan, "Integrated Analysis of ASTER and Landsat ETM Data to Map Exploration Targets in the Muteh Gold-Mining Area, IRAN," 5th International Symposium on Spatial Data Quality, Enschede, 2007.

[6] H. Azizi, M. A. Tarverdi and A. Akbarpour, "Extraction of Hydrothermal Alterations from ASTER SWIR Data from East Zanjan, Northern Iran," Advances in Space Research, Vol. 46, No. 1, 2010, pp. 99-109.

doi:10.1016/j.asr.2010.03.014

[7] A. B. Pour and M. Hashim, "Identifying Areas of High Economic-Potential Copper Mineralization Using ASTER Data in the Urumieh-Dokhtar Volcanic Belt, Iran," Advances in Space Research, Vol. 49, No. 4, 2012, pp. 753-769. doi:10.1016/j.asr.2011.11.028

[8] J. C. Mars and L. C. Rowan, "Radiometer (ASTER) Data and Logical Operator Algorithms Arc, Iran, Using Advanced Spaceborne Thermal Emission and Reflection Regional Mapping of Phyllic and Argillic Altered Rocks in the Zagros Magmatic," Geosphere, Vol. 2, No. 3, 2006, pp. 161-186. doi:10.1130/GES00044.1

[9] R. Poormirzaee and M. M. Oskouei, "Use of Spectral Analysis for Detection of Alterations in ETM Data, Yazd, Iran," Applied Geomatics, Vol. 2, No. 4, 2010, pp. 147154. doi:10.1007/s12518-010-0027-8

[10] S. A. Ali and S. Pirasteh, "Geological Applications of Landsat Enhanced Thematic Mapper (ETM) Data and Geographic Information System (GIS): Mapping and Structural Interpretation in South-West Iran, Zagros Structural Belt," International Journal of Remote Sensing, Vol. 25, No. 21, 2004, 4715-4727. doi:10.1080/01431160410001688295

[11] A. Aghanabati, "Geology of Iran," Geological Survey of Iran, 2004, $622 \mathrm{p}$.

[12] H. Watanabe and K. Matsuo, "Rock type Classification by Multi-Band TIR of ASTER," Geoscience Journal, Vol. 7, No. 4, 2003, pp. 347-358. doi:10.1007/BF02919567

[13] E. V. Yetkin, Toprak and M. L. Suezen, “Alteration Mapping By Remote Sensing: Application to HasandağMelendiz Volcanic, Complex," Geo-Imagery Bridging Continents 10th ISPRS Congress, Istanbul, 2004.

[14] J. W. Boardman, F. A. Kruse and R. O. Green, "Mapping Target Signatures via Partial un Mixing of AVIRIS Data," Summaries, Proceedings of the 5th JPL Airborne Earth Science Workshop, Pasadena, 1995, pp. 23-26

[15] A. A. Green, M. Berman, P. Switzer and M. D. Craig, "A Transformation for Ordering Multispectral Data in Terms of Image Quality with Implications for Noise Removal," IEEE Transactions on Geoscience and Remote Sensing, Vol. 26, No. 1, 1988, pp. 65-74. doi:10.1109/36.3001

[16] A. B. Pour, M. Hashim and M. Marghany, "Using Spectral Mapping Techniques on Short Wave Infrared Bands of ASTER Remote Sensing Data for Alteration Mineral Mapping in SE Iran," International Journal of the Physical Sciences, Vol. 6, No. 4, 2011, pp. 917-929.

[17] S. Myint, K. Aung and T. Isao, "Application of Remote Sensing Techniques on Iron Oxide Detection from ASTER and Landsat Images of Tanintharyi Costal Area, Myanmar," Scientific and Technical Reports of Faculty of Engineering and Resource Science No. 26, Akita University, Akita, 2005, pp. 21-28.

[18] A. P. Crosta and J. M. Moore, "Enhancement of Landsat Thematic Mapper Imagery for Residual Soil Mapping in SW Minais Gerais State, Brazil: A Prospecting Case History in Greenstone Belt Terrain," Proceedings of the 7th 
Thematic Conference on Remote Sensing for Exploration Geology, 1989.

[19] M. Khaleghi and H. Ranjbar, "Alteration Mapping for Exploration of Porphyry Copper Mineralization in the Sarduiyeh Area, Kerman Province, Iran, Using ASTER SWIR Data," Australian Journal of Basic and Applied Sciences, Vol. 5, No. 8, 2011, pp. 61-69.

[20] A. Malekzadeh, M. H. Karimpour, C. R. Stern and S. A. Mazaheri, "Hydrothermal Alteration Mapping in SW Birjand, Iran, Using the Advanced Spaceborne Thermal
Emission and Reflection Radiometer (ASTER) Image processing," Journal of Applied Sciences, Vol. 9, No. 5, 2009, pp. 829-842.

[21] F. A. Kruse, J. W. Boardman, A. B. Lefkoff, K. B. Heidebrecht, A. T. Shapiro, P. J. Barloon and A. F. H. Goetz, "The Spectral Image Processing System (SIPS) - Interactive Visualization and Analysis of Imaging Spectrometer Data," Remote Sensing of Environment, Vol. 44, No. 2-3, 1993, pp. 145-163. 